\title{
А.Н. Тепляшина
}

\section{ПРОФЕССИОНАЛЬНАЯ КРИТИКА РЕСТОРАНОВ В ДЕЛОВОЙ ПРЕССЕ КАК ФАКТОР ЖАНРОВОЙ МОДИФИКАЦИИ РЕЦЕНЗИИ}

\begin{abstract}
В статье рассматривается заметный компонент структуры деловой газеты - рубрика о деятельности ресторанов. Целью является отражение процесса формирования нового тематического направления, оказавщего влияние на эволюцию жанра реиензии. Задача автора - показать, что до 1990 г. в СМИ бытовали жанровые модификации рецензий на книги, спектакли, фильмы. Проанализированный материал позволяет сделать вывод, что «ресторанная критика» также требует от журналиста высокого профессионализма, личной культуры.

Ключевые слова: жанр, деловая пресса, колумнистика, ресторанная критика, тематика, досуг, авторская колонка.
\end{abstract}

В советский период отечественной истории журналисты о системе общественного питания писали исключительно в жанре фельетона, используя все возможные выразительные средства комического, от иронии до сарказма. Не оспаривая правомерность приоритета жанра фельетона в описании советского быта, обратим внимание на отсутствие альтернативных точек зрения не только на деятельность заведений общественного питания, но и на иные объекты, связанные с досугом. Считалось, что эта сфера, исключительно развлекательная, следовательно, поверхностная, малополезная, непродуктивная и даже вредная, не заслуживает внимания прессы. Однако досуг - часть нерабочего времени, которая используется не только для отдыха и восстановления сил, но и для физического, духовного развития человека.

Интерес к досугу как знаковому явлению повседневности проявила в конце XX - нчале XXI в. философская наука [1-6]. Широкую известность в России получили типологические и лингвистические исследования досуговой журналистики, проведенные в Санкт-Петербургском государственном университете. Анализ медиатекстов показал, что журналистский дискурс сферы досуга связан с темами культуры, хобби, моды и стиля жизни, путешествий, кулинарии. Абсолютно очевидно, что досуговые практики во многом зависят от величины денежных затрат и характера финансирования свободного времени, которое может осуществляться в виде меценатства, спонсорства, государственной поддержки, личных инвестиций индивида. Именно поэтому так возросла значимость досуга, которая усиливается и коммерциализацией досуговой сферы, ее индустриализацией, коммуникацией с бизнесом [7. С. 8].

В деловой прессе постсоветской России заметным явлением стала рубрика, посвященная разносторонней деятельности современных ресторанов. Критик, под влиянием конвергентных процессов трансформировалась, менялся вектор оценок. В первое время для журналистов, получавших редакционное задание написать о ресторане, фирменных блюдах, культуре обслужи- 
вания и т.д., его выполнение оказывалось сопряжено с рядом трудностей: в частности, (еще неявная) конвергенция журналистики и рекламы приводила к очевидным этическим конфликтам; у журналистов не было опыта позитивного описания ресторанной культуры, не было критериев оценки ресторанов, кафе, баров, возвращенных из далекого прошлого трактиров. Каждый корреспондент, взявшийся за новую тему, создавал собственную систему оценки: в результате одни выставляли баллы за обслуживание, винную карту, интерьер, атмосферу, соотношение цен и качества; другие оценивали заведение на основе отзывов посетителей; третьи детально описывали плюсы и минусы поданных блюд; некоторым было важно раскрыть основную концепцию ресторана. Отсутствие критериев делало ресторанную критику субъективной, случайной, нередко вводящей читателя в заблуждение.

Заметки о еде в периодических изданиях, воскресные приложения с кулинарными обзорами, рецептами и подробными инструкциями приготовления блюд - данный информационный массив способствовал образованию ниши ресторанной критики в прессе, которая, в свою очередь, стимулировала развитие ресторанного бизнеса. Открытие нового ресторана стало повседневным явлением. Термин «ресторанный критик» прочно укрепился в периодической печати и в речевом пространстве эпохи. Журналисты ярко и талантливо, в лучших традициях русской классической литературы, писали об истории блюд, умении их готовить, подавать и есть, об изысканности интерьеров, белизне и нарядности скатертей, кружеве салфеток, эстетике дизайна. Развитию и оформлению кулинарного бизнеса посвящались специальные колонки и даже целые полосы ресторанных новостей и модной ресторанной критики [8]. Так сформировалась культура критического отношения к ресторанному обслуживанию, особенностям кухни, сочетаемости блюд, вкусовой палитре.

В 1992 г. «КоммерсантЪ» ввел должность «ресторанный критик», занимаемую уже более 20 лет Д. Цивиной, и создал выпуск еженедельного приложения «Weekend» с подборкой рецензий по интересным новинкам и фестивалям ресторанной индустрии. Кроме Цивиной, колонку ресторанной критики в этом же издании вела Е. Герусова, которая в настоящее время известна как театральный критик.

Во второй половине 1990-х гг. в России стали издаваться специализированные газеты и журналы двух видов: издания для профессионалов ресторанного дела (владельцев кафе и ресторанов, PR-менеджеров, артдиректоров, поставщиков продуктов питания, алкогольной и табачной продукции); издания для потребителей - тех, кто любит питаться и отдыхать вне дома и готов тратить на это деньги. Ресторанная тематика не ограничена по возможностям, поэтому постоянно появляются новые рецепты, открываются рестораны разных кухонь мира, меняется уровень популяризации той или иной кулинарной линии, что позволяет журналистам совершенствоваться в познаниях. Можно констатировать, что сложился тип ресторанного критика как независимого профессионала, гурмана, выполняющего основную задачу: помогать аудитории ориентироваться в многообразии кулинарных предпочтений и предложений на ресторанном рынке. 
Стержневым элементом журналистской практики является этика. Не составляет секрета, что многие журналисты считают написание рецензий на ресторанную тематику дополнительным заработком и рассматривают походы в рестораны исключительно как возможность сотрудничества с руководством заведения. Нередки случаи заказных статей с целью повысить посещаемость ресторана, организовать рекламную кампанию, «утопить» конкурентов.

А.Н. Назайкин предлагает рассматривать конвергенцию журналистики, PR и рекламы в виде трех цветов: «белого», «черного» и «серого» [9] «Черный» - когда заказчики публикаций договариваются с журналистами напрямую, в обход редакции и рекламной службы данного СМИ. Заинтересованная организация просто платит готовящему материал корреспонденту.

«Серый» цвет отношений - это публикация официально оплаченной информации в виде обычного редакционного материала - заметки, репортажа, рецензии. В этом случае деньги от заказа поступают не в карман отдельного журналиста, а в бюджет конкретного СМИ. Многие российские СМИ не маркируют оплаченную информацию, просто печатая наряду с обычными редакционными материалами.

К «серым» методам можно причислить давление, оказываемое на редакции крупными рекламодателями. Компании, вкладывающие в бюджет какого-нибудь СМИ солидные рекламные суммы, понимают собственную значимость для редакции, поэтому часто мягко намекают на публикации поддерживающих статей, интервью, заметок и рецензий. Редакции склонны учитывать «пожелания» важных клиентов.

Третий цвет «белый». При работе «по-белому» представитель заинтересованной компании ничего не платит ни журналисту, ни его редакции. СМИ размещает информационный материал бесплатно, просто на основании того, что он интересен аудитории издания, телеканала или радиостанции. Это подтверждается словами А. Васильева, шеф-редактора и совладельца издательского дома «КоммерсантЪ», члена Совета директоров ЗАО «КоммерсантЪ. Издательский Дом» (2006-2010 гг.): «В «Коммерсанте» трудно разместить «заказуху», так как у нас очень жесткая концепция, жесткий формат статей. Однако дать руку на отсечение, что в «Коммерсанте» никто не берет, я не могу. Но это явно не модно у нас. Никто ни перед кем таким хвалиться не будет. Бывают, конечно, статьи, которые оказываются кому-то на руку. И мы даже знаем, что кто-то из пиарщиков у кого-то за это получил деньги. Но если действительно есть новостной повод, мы такие статьи публикуем. Читатель не виноват» [10]. Однако, по утверждению Д. Алексеева, известного медиакритика, в России большинство статей данной направленности заказные: «У нас мнение критика стоит недорого... Владельцы рестораций расценивают ресторанных критиков исключительно в качестве бесплатной рекламы, приглашают... попробовать новое меню, чтобы затем, дождавшись, как всегда, положительно-описательной рецензии, вывесить ее в качестве рекламной статьи у себя на сайте с указанием издания, где она была опубликована» [11].

Д. Алексеев - активный противник искусственных пищевых красителей, консервантов и различных усилителей вкуса - выступил с обращением к компании «Unilever» воздвигнуть памятник, символизирующий собой кулинарную эволюцию. В вершине предлагается поставить телеведущего А. Зи- 
мина, снявшегося в рекламе супового кубика Knorr и называющего его «лучшим открытием в кулинарии» и «душой своей кухни [12]. Состав кубика включает в себя глутамат, инозинат и гуанилат натрия, крахмал, ароматизаторы, красители и прочие вредные ингредиенты. Вполне ясна причина, по которой известный журналист, гастрономический профессионал и «отец ресторанной критики» согласился на рекламу.

Критика может выражаться в разных формах и видах, ресторанная же критика находит оптимальное воплощение в авторских колонках. Авторская колонка сегодня переживает пик популярности, являясь едва ли не самым востребованным сегментом газеты или журнала. В Интернете ежедневно размещается много отзывов о том или ином заведении людей, далеких от профессиональной критики, однако у авторитетных авторов, таких как Д. Цивина или Д. Алексеев, есть свои колонки в печатных изданиях и блоги в социальных сетях.

По мнению Ю.А. Гордеева, колонка - это частный случай авторской рубрики в периодическом издании с учетом того, что авторский характер здесь распространяется и на коммуникативный блок текста [13]. Известный блогер A. Маратов, колумнист журнала «F5», считает, что колонка - это рубрика, персонально закрепленная за конкретным журналистом, по сути своей - авторское высказывание, близкое по жанру к эссе [14]. В Россию колонка пришла из западной журналистики. Вначале колонка была редким явлением в деловой прессе, однако за последнее десятилетие она, как и фельетон, в XVIII в. лишь часть газетной полосы, трансформировалась в жанр. Особенностью этого жанра является его способность приобретать различные модификации в зависимости от воли автора текста - колумниста, регулярно выступающего в СМИ.

С.С. Ярцева, исследующая традиции персонифицированного письма в русской журналистике, считает, что колумнистика, пришедшая в российские СМИ с Запада в начале 1990-х гг., «не была явлением для России абсолютно новым». По ее мнению, возможности для бурного развития авторской колонки в России появились еще в начале XX в., когда газеты приобрели огромную общественную силу, сделавшись органами возникающих политических партий. Именно тогда многие публицисты начали выражать свое мнение по поводу происходящего в колонках и передовых статьях. К первым российским колумнистам Ярцева относит М.Н. Каткова с циклом авторских статей в «Московских ведомостях»; А.С. Суворина с его «Маленькими письмами» в газете «Новое время»; А.М. Горького с циклом «Несвоевременные мысли» в газете «Новая жизнь». Автор резюмирует, что «...в дореволюционной России были все предпосылки к появлению колумнистики, и если бы не октябрьская революция, приведшая к возникновению тоталитарного государства, в котором интерес к отдельной личности с ее мнением был невозможен, то, скорее всего, российская колумнистика пошла бы по тому же пути и развивалась так же плодотворно, как и в западной журналистике. Однако этот процесс был искусственно остановлен. И именно этой искусственостью объясняется тот факт, что, как только российское общество стало более открытым, колумнистика на страницах отечественных изданий возникла сразу, быстро распространилась и прижилась» [15. С. 28]. 
В начале своей деятельности в качестве колумниста Д. Цивина писала эмоциональные, восторженные тексты о московских ресторанах и о фестивалях мировой кухни, теперь ее произведения лаконичны, в контенте преобладают сухие факты. Автор объясняет это тем, что сегодня ее удивить намного сложнее, чем несколько лет назад. Ранние обзоры журналиста пестрили детализированным меню: «Жареный судак, маринованный в сметане, подается с рагу из мидий и сладкой разноцветной паприки. Тигровые креветки дополняет вязкое ризотто с томатным соусом. Баранья корейка сервируется соусом из зеленого перца и картофелем, приправленным розмарином» [16]. В рецензиях не было оценки сервиса, работы официантов и метрдотелей; лишь описание интерьера, краткая история создания заведения и подробнейшее меню и много терминологических ошибок.

Заметки Цивиной строятся без лишних деталей: в основном это описание общей концепции заведения и одного-двух лучших, по мнению автора, блюд: «...сильно выделяется одно эксклюзивное блюдо - ямало-ненецкая годовалая оленина... оленина эта имеет необычайно интересную фактуру и очень яркий вкус, готовится medium rare и подается со сладкими персиками» [17].

По мнению Цивиной, один из признаков профессионализма в ресторанной критике - смелость, что означает дегустацию чего угодно, будь то змея или страус. Главное в оценке - объективность, умноженная на юмор и умеренность: критики ходят в рестораны не есть, а «снимать пробу». Чем журналист и занимается пять дней в неделю: ходит в рестораны, отдавая предпочтение недавно открывшимся; общается с шеф-поварами и дегустирует различные блюда. Мнение журналистки ценится в ресторанной индустрии очень высоко.

Другой яркий представитель ресторанных критиков - Д. Алексеев. Первоначально кулинария была его хобби, но со временем увлечение переросло в профессию, и теперь критик является вице-президентом Ассоциации ресторанно-гастрономических обозревателей. Рецензии Алексеева публикуются на страницах изданий «FHM», «Forbes Style», «Departures», «Yachting», в электронных газетах «Дни.ру» и «Гастроном». Алексеев в своих отзывах объективен и беспристрастен, всегда ратует за правильное питание, однако некоторые его статьи ориентированы на узкий круг читателей, сведущих в кулинарии и ресторанном бизнесе. Такие обзоры содержат термины профессиональной тематики: «сыворотка от пармиджано реджано для производства единственно верной разновидности прошутто ди Парма»; «пена из мортаделы с миниатюрными овальными ньокки из обезвоженного хлеба»; частое упоминание «звездной» системы Michelin, без примечаний о том, что это за система и на чем она специализируется. Но все это в гастрономических статьях; рецензии же публицистичны, обстоятельны, подробны, не лишены юмора, честны и объективны.

Алексеев использует балльную систему от 1 до 5 в оценке следующих категорий: кухни, сервиса, интерьера, атмосферы, напитков, соотношения цены и качества. Строится отзыв по стандартному принципу: вначале критик повествует об истории создания ресторана, следом идет описание интерьера и декора, далее автор рассказывает о кухне, презентации блюд, обязательно указывает плюсы и минусы заведения, напоследок остается таблица с 
баллами. Язык критика метафоричен, не лишен эмоциональной окраски, побуждает аудиторию отправиться в понравившееся по отзыву заведение. Высказывания журналиста-медиакритика заставляют читателя задуматься об эстетической и духовной целях похода в ресторан: «Дом Баккара - ода роскоши и изобилию. И приходить сюда следует ни в коем случае не ради удовлетворения физиологических потребностей, а исключительно во имя каких-то иных патетических целей: созерцания сюрреалистических неоренессансных декораций, любования плодами "эпохи процветания" и вкушения тонких ароматов французской кухни» [18]. Колонки Алексеева пользуются популярностью среди читателей, его мнению доверяют, к нему прислушиваются.

В ряде случаев критик использует профессиональные термины без определения понятия, что затрудняет чтение и понимание рецензии: «Еще один приятный нюанс: в «Maison Baccarat» есть не только открытая кухня, но и table du chef. Правда, приходить на Эмерле ради того, чтобы все хорошенько разглядеть, а затем плотно перекусить, совершенно бессмысленно» [18]. Что такое загадочное «table du chef», остается только догадываться людям, не сведущим в кулинарной терминологии, и пытаться понять смысл, последовательно переводя каждое слово. Также автор не всегда последовательно приводит к заключению в рецензии, отзыв может закончиться совершенно неожиданно для читателя: «И наконец, самый главный недостаток ресторана - цены. Я, конечно, понимаю, что посетители Третьяковского проезда - люди не скупые. Однако требовать с гостей своего Дома по 900 рублей за стакан свежевыжатого сока несколько негостеприимно» [18]. Далее следует таблица с выставленными баллами.

По мнению Д. Алексеева, задача ресторанной критики состоит в том, чтобы оградить гурманов от негативных «нюансов», однако сейчас эта суть сведена исключительно к перечислению блюд и описательных подробностей. Мало того, автор приводит в пример факт дезинформирования журналистами аудитории, вспомнив показательную историю Анатолия Комма. Комм открыл в Женеве ресторан Green, который вскоре попал в путеводитель Michelin. Стоит отметить, что гид содержит информацию о заведениях по географическому принципу, о недорогих закусочных и кафе. Однако сам факт присутствия заведения в путеводителе ресторатор стал «трактовать в многочисленных интервью в качестве своего первого шага к звезде, которую он (по его словам) должен был получить уже в течение ближайших нескольких месяцев» [19]. Журналисты растиражировали информацию и теперь иначе как «единственный русский шеф, попавший в Michelin» Комма не зовут. И это несмотря на то, что ресторан «Green» уже давно закрылся и пропал из гида.

Одним из самых авторитетных ресторанных критиков в России по праву считается Алексей Зимин. Кроме того, что Зимин является журналистом, он еще и повар, преподаватель кулинарной школы и куратор кухни кафе «Ragout» в Москве. За плечами критика есть специальное образование в авторитетной лондонской школе поваров «Cordon Bleu» и стажировка у таких асов кулинарии, как Мишель Герар и Раймон Блан. Рецензии Зимина можно прочесть в тематических колонках изданий «Коммерсантъ» и «Ведомости». Так- 
же у журналиста есть кулинарный блог на сайте «Афиша-еда», а особой популярностью у аудитории пользуются кулинарные передачи «Еда» на МенюТВ и «Готовим с Алексеем Зиминым» на НТВ. Критик выпустил уже 3 книги, посвященные кулинарии: «Кухня навсегда» рассказывает о лучших рецептах мировой кухни, «Кухня рынка» - о приготовлении сезонных блюд и фактически представляет собой кулинарный календарь, а «Кухня супермаркета» предлагает оригинальные рецепты из общедоступных продуктов.

Возрастание интереса к хорошей кухне, популярность гастрономических изданий и разнообразных кулинарных шоу Зимин считает общемировой тенденцией, связанной с тем, что еда является одним из самых важных моментов в жизни человека, формой познания самого себя. Как только процесс насыщения перестает быть просто условием выживания, приготовление еды переходит в разряд искусства. В настоящее время происходит естественный процесс заимствования кулинарных традиций. По мнению Зимина, любая национальная кухня не должна оставаться герметически замкнутым миром. Он не согласен с теми, кто говорит об исчезновении традиционной русской кулинарии, и считает процесс впитывания новых идей вполне естественным и благоприятным [20].

Что касается ресторанной критики, то, по мнению журналиста, люди стали более фундаментально относиться к тому, что они едят: «Их интересуют все обстоятельства появления на тарелке того или иного продукта. Они уже не ходят в ресторан, чтобы поразиться чему-то. Они никому не верят на слово, у них уже есть мнение, они сами себе ресторанные критики» [21].

Однако это не мешает Зимину самому заниматься оценкой ресторанов столицы. Делает он это несколько иным способом, нежели его коллеги: в начале обзоров автор приводит размышления на гастрономические темы - эволюция гастрономической культуры в России или диверсификация ресторанного рынка - и затем плавно переходит на какое-нибудь заведение. В обзорах журналиста постоянно переплетаются насущные проблемы общества и гастрономическая культура. В последнее время Зимин все чаще обращается к общественным проблемам гастрономической культуры, нежели критикует рестораны. Теперь его волнуют совместное развитие фастфуда с высокой кухней; еда, предлагаемая в мировых аэропортах; обучение и опыт в области кулинарии.

Сейчас в России наблюдается пик популярности ресторанной культуры. Каждую неделю открываются новые заведения, рост предложения на рынке общественного питания идет вслед за растущим спросом. Ресторанные критики помогают потребителю сориентироваться в существующем многообразии и сделать оптимальный выбор. Однако профессиональная оценка ресторанных заведений требует особых знаний, опыта, развитой личной культуры и, несомненно, литературных способностей. Важно не только объективно оценить ресторан, но и суметь красиво и грамотно донести мысль до читателя. Следует помнить также и о том, что как бы человек не стремился к объективной оценке окружающей действительности, его интерпретация реальности всегда будет субъективной. Любую информацию человек пропускает через призму собственных ощущений, поэтому, как бы автор не старался дать объективную оценку ресторану, его суждение будет содержать определенный 
элемент субъективности. Вместе с тем это своеобразный катализатор прогресса и, в идеале, независимый источник мнения; ресторанная критика мотивирует, дает возможность осознать, принять и исправить ошибки, а также ориентирует аудиторию в возможностях проведения досуга и формирует здоровые гастрономические привычки.

Ресторанный критик сегодня - это независимый профессионал, гурман, основная задача которого - помогать аудитории ориентироваться в многообразии кулинарных предпочтений и предложений на ресторанном рынке. Решение этой задачи требует высокого профессионализма, обширных теоретических и практических познаний в области ресторанного бизнеса; безупречного вкуса и умения различать тончайшую вкусовую гамму блюд; объективности и непредвзятости, личной культуры. Эти требования тем более актуальны, что ресторанная тематика не ограничена по возможностям: постоянно появляются новые рецепты, открываются рестораны с комбинированной кухней, растет уровень их доступности, что позволяет привлекать новых посетителей.

Выполняя просветительскую функцию, ресторанная критика дает возможность правильно ориентироваться в сфере предлагаемых услуг, повышает культурный уровень потенциальных потребителей.

\section{Литература}

1. Лотман Ю.М. Беседы о русской культуре: Быт и традиции русского дворянства (XVIII начало ХІХ века). СПб.: Арт-СПб., 1994. 399 с.

2. Богданов К.A. Повседневность и мифология: Исследования по семиотике фольклорной действительности. СПб.: Литера, 2001. 247 с.

3. Лелеко В.Д. Пространство повседневности в европейской культуре. СПб.: Аврора, 2002. $176 \mathrm{c}$.

4. Шюи А. Трансцендентность природы и общества: Символы. О множествах реальности // Шюц А. Избранное: Мир, светящийся смыслом. М., 2004. 1056 с. $310 \mathrm{c}$.

5. В перспективе культурологии: повседневность, язык, общество. М.: Асток-пресс, 2005.

6. Рис Н. Русские разговоры: культура и речевая повседневность эпохи перестройки. М.: Айрис-пресс, 2005. $338 \mathrm{c}$.

7. Дускаева Л.Р., Цветова Н.С. Журналистика сферы досуга: учеб. пособие. СПб.: Юнипресс, 2012. $304 \mathrm{c}$.

8. Нерсесова T.E. Сервисное рецензирование как особая предметная область оценочной деятельности журналиста. М.: Медиаскоп, 2011. № 2. URL: http:// www.mediascope.ru /node/85/

9. Назайкин А.Н. Три цвета медиарилейшнз. М.: Медиаскоп, 2008. № 1. URL: http:// www.mediascope.ru /node/208/

10. Сваровский Ф. Информационные войны, или Как специалисты по PR покупают СMИ // Ведомости. 2002. 28 янв.

11. Алексеев Д. Критика ресторанной критики // http://vz.ru/ columns/ 2008/2/26/147629.html

12. «Великое» открытие Зимина, или Усилитель Вкуса решает все // www.argo-media.ru/ 2009-05-10-12-46-30/364-knorr.html

13. Носков А. От ценителя до циника один шаг. URL: http://resto74.ru/ restaurateur/ noskovcritics.html

14. Маратов А. Авторский жанр. URL: http:// www. columnizm.livejournal.com/ 5873.html

15. Ярцева С.С. Традиции персонифицированного письма в русской журналистике: Материалы Всерос. науч.-практ. конф. «Проблемы массовой коммуникации: новые подходы», 2931 октября 2007 г. Ч. 2 / под ред. В.В. Тулупова. Воронеж, 2007. С. 27-30.

16. Цивина Д. Ресторанная критика // Коммерсантъ. 1997.10 апр.

17. Цивина Д. «Кадриль» с оленем // Коммерсантъ Weekend. 2013. 6 дек. 
18. Алексеев Д. Ресторанная критика: Maison Baccarat. URL: http:/www.dni.ru/ style/ 2008/5/27/ 143085.html

19. Алексеев Д. Критика ресторанного критика // Взгляд. 2008. 26 февр.

20. Алексей Зимин - кулинарный путешественник. URL: http://www.peoples.ru/ science/ travellers/ alexey_zimin/index.html

21. The Village: Алексей Зимин и Вадим Лапин: Что творится в гастрономии? URL: http:// www.the-village/city/teatalks/127481-eda

\section{PROFESSIONAL CRITICISM OF RESTAURANTS IN THE BUSINESS PRESS AS A FACTOR OF GENRE MODIFICATION OF REVIEWS.}

Tomsk State University Journal of Philology, 2015, 2(34), pp. 195-204.

DOI 10.17223/19986645/34/16

Teplyashina Alla N., Saint-Petersburg State University (Saint-Petersburg, Russian Federation). E-mail: a-nik@list.ru

Keywords: the genre, the business press, columnism, restaurant critic, themes, leisure, author column.

In the business press in post-Soviet Russia noteworthy is the part about the diverse activities of modern restaurants. At first, the absence of criteria makes restaurant criticism subjective and random. Notes in periodicals, Sunday supplements with culinary reviews, recipes and detailed instructions for cooking form a niche for restaurant criticism in the press. Criticism stimulates the development of the restaurant business.

A number of topics go under restaurant news and criticism. It forms the direction in business journalism-related professional assessment of restaurant service, national cuisine, the combination of dishes, taste palette. The restaurant topic is growing: there were always new recipes, new restaurants of different cuisines of the world opened, the level of culinary line popularization changed. Criticism can be expressed in different forms and genres, but restaurant criticism finds its best form in opinion columns. Author's column today is experiencing a boom in popularity, being perhaps the most popular segment of a newspaper or a magazine. There is a lot of feedback about a particular place from people far from professional criticism on the Internet on a daily basis, but well-known journalists have their own columns in publications and blogs in social networks.

Each correspondent takes on a new theme, creates his or her own system of assessment. Some give points for service, wine list, interior, atmosphere, price and quality; some evaluate places on the basis of reviews; some describe in detail the pros and cons of the served dishes; some reveal the basic concept of the restaurant.

The study leads to a conclusion that there is a type of restaurant criticism as an independent professional, gourmet. Professional critics perform a basic task: they help the audience to navigate the diverse culinary preferences and suggestions on restaurant market. The core element of practice is ethics. Unfortunately, many journalists consider writing reviews for restaurants as an additional income. They consider going to restaurants as an opportunity of cooperation with the administration of a place. Sponsored articles are frequently published.

The study materials allow to conclude that the purpose of these articles is to increase the rating of the restaurant, attendance, organization of advertising campaigns, elimination of competitors.

\section{References}

1. Lotman Yu.M. Besedy o russkoy kul'ture: Byt i traditsii russkogo dvoryanstva (XVIII - nachalo $X I X$ veka) [Conversations about Russian culture: the life and traditions of the Russian nobility (18th early 19th centuries)]. St. Petersburg: Art-Spb. Publ., 1994. 399 p.

2. Bogdanov K. A. Povsednevnost' $i$ mifologiya: Issledovaniya po semiotike fol'klornoy deystvitel'nosti [Daily life and mythology: Studies in semiotics of folk reality]. St. Petersburg: Litera Publ., 2001. 247 p.

3. Leleko V.D. Prostranstvo povsednevnosti v evropeyskoy kul'ture [The space of everyday life in European culture]. St. Petersburg: Avrora Publ., 2002. 176 p.

4. Schutz A. Izbrannoe: Mir, svetyashchiysya smyslom [Selected works: world glowing with sense]. Moscow: Rossiyskaya politicheskaya entsiklopediya Publ., 2004. 1056 p.

5. V perspektive kul'turologii: povsednevnost', yazyk, obshchestvo [In the aspect of cultural studies: daily life, language and society]. Moscow: Astok-press Publ., 2005. 310 p. 
6. Ris N. Russkie razgovory: kul'tura i rechevaya povsednevnost' epokhi perestroyki [Russian talks: Culture and everyday speech of perestroika]. Moscow: Ayris-press Publ., 2005. 338 p.

7. Duskaeva L.R., Tsvetova N.S. Zhurnalistika sfery dosuga [Journalism of leisure sphere]. St. Petersburg: Yunipress, 2012. 304 p.

8. Nersesova T. E. Servisnoe retsenzirovanie kak osobaya predmetnaya oblast' otsenochnoy deyatel'nosti zhurnalista [Service review as a special subject area of evaluation activity of the journalist]. Moscow: Mediaskop Publ., 2011, no. 2. Available from: www.mediascope.ru/node/85/.

9. Nazaykin A.N. Tri tsveta mediarileyshnz [Three Colors of Media Relations]. Moscow: Mediaskop, 2008, no. 1. Available from: www.mediascope.ru /node/208/

10. Svarovskiy F. Informatsionnyy voyny, ili kak spetsialisty po PR pokupayut SMI [Information wars, or how PR specialists buy media]. Vedomosti, 2002, 28 January.

11. Alekseev D. Kritika restorannoy kritiki [Criticism of restaurant criticism]. Available from: http://vz.ru/columns/2008/2/26/147629.html.

12. "Velikoe" otkrytie Zimina, ili Usilitel' Vkusa reshaet vse [The "Great" discovery of Zimin, or flavor enhancers solve everything]. Available from: www.argo-media.ru/2009-05-10-12-46-30/364knorr.html.

13. Noskov A. Ot tsenitelya do tsinika odin shag [From connoisseur to cynic is one step]. Available from: resto74.ru/restaurateur/noskov-critic p. html.

14. Maratov A. Avtorskiy zhanr [Author genre]. Available from: www.columnizm. livejournal.com/ 5873.html.

15. Yartseva S.S. [Tradition of personalized letters in Russian journalism]. Materialy vserossiyskoy nauchno-prakticheskoy konferentsii "Problemy massovoy kommunikatsii: novye podkhody" [Proceedings of the All-Russian Scientific-Practical Conference "Problems of Mass Communication: New Approaches"]. Voronezh, 2007, pt. 2, pp. 27-30. (In Russian).

16. Tsivina D. Restorannaya kritika [Restaurant criticism]. Kommersant""', 1997, 10 April.

17. Tsivina D. "Kadril"" s olenem ["Quadrille" with a deer]. Kommersant"'" Weekend, 2013, 6 December.

18. Alekseev D. Restorannaya kritika: Maison Baccarat [Restaurant criticism: Maison Baccarat]. Available from: www.dni.ru/style/2008/5/27/143085.html.

19. Alekseev D. Kritika restorannogo kritika [Criticism of a restaurant critic]. Vzglyad, 2008, 26 February.

20. Aleksey Zimin - kulinarnyy puteshestvennik [Alexei Zimin - the culinary traveler]. Available from: www.peoples. ru/science/travellers/alexey_zimin/index.html.

21. The Village: Aleksey Zimin i Vadim Lapin: Chto tvoritsya v gastronomii? [The Village: Alexei Zimin and Vadim Lapin: What's happening in gastronomy?]. Available from: www.thevillage/city/teatalks/127481-eda. 